\title{
Allocation of Tutors and Study Centers in Distance Learning Using Geospatial Technologies
}

\author{
Shahid Nawaz Khan ${ }^{1}$ (1), Kamran Mir ${ }^{2}$ (D), Ali Tahir ${ }^{1, *(1)}$, Arshad Awan ${ }^{2}$ (1) , Zaib un Nisa ${ }^{1}$ and \\ Syeda Areeba Gillani ${ }^{3}$ \\ 1 Institute of Geographical Information Systems, School of Civil and Environmental Engineering, \\ National University of Sciences and Technology, Islamabad 44000, Pakistan; \\ snawaz.ms16igis@igis.nust.edu.pk (S.N.K.); zaibunnisa12@igis.nust.edu.pk (Z.u.N.) \\ 2 Department of Computer Sciences, Allama Iqbal Open University, Islamabad 44000, Pakistan; \\ kamran.mir@aiou.edu.pk (K.M.); m99arshad@aiou.edu.pk (A.A.) \\ 3 Institute of Geo-Information and Earth Observation, Pir Mehr Ali Shah Arid Agriculture University, \\ Rawalpindi 46000, Pakistan; syedaareebagillani@gmail.com \\ * Correspondence: ali.tahir@igis.nust.edu.pk; Tel.: +92-51-9085-4476
}

Received: 2 April 2018; Accepted: 9 May 2018; Published: 11 May 2018

\begin{abstract}
Allama Iqbal Open University (AIOU) is Pakistan's largest distance learning institute, providing education to 1.4 million students. This is a fairly large setup across a country where students are highly geographically distributed. Currently, the system works using a manual approach, which is not efficient. Allocation of tutors and study centers to students plays a key role in creating a better learning environment for distance learning. Assigning tutors and study centers to distance learning students is a challenging task when there is a huge geographic spread. Using geospatial technologies in open and distance learning can fix allocation problems. This research analyzes real data from the twin cities Islamabad and Rawalpindi. The results show that geospatial technologies can be used for efficient and proper resource utilization and allocation, which in turn can save time and money. The overall idea fits into an improved distance learning framework and related analytics.
\end{abstract}

Keywords: geospatial technologies; distance learning; resource allocation; AIOU

\section{Introduction}

Distance education is acquired by learners when the opportunity for face-to-face learning is limited or when there are not enough resources to cater to learners' needs. There are educational disciplines in which there may not be a need to deliver lectures, and therefore several modes of communication are used by educators and distance learners [1]. Many teaching strategies are employed by distance educators to deliver content to distance learners in open and distance learning environments. The continuous growth of distance education has created new opportunities for distance learners and educators. Simultaneously, continuous improvements for innovation in delivery techniques have also occurred. Educators have always focused on enhancing interactivity, which is vital in open and distance learning. The proliferation of disruptive technologies has created an opportunity to achieve maximum levels of interaction, which is evident from current trends of technology usage in distance learning [2].

Allama Iqbal Open University (AIOU; http:/ / www.aiou.edu.pk) is Pakistan's largest distance education institute, providing distance education to students in almost every field, from higher secondary-level to doctorate-level studies. The university admits candidates in different disciplines such as arts, management, and science, where each student is assigned a tutor who is responsible for marking the student's assignments. A tutor is also responsible for formal meetings, known as 
workshops, in study centers allocated to students by the university. Currently, the university uses a manual system for the allocation of students and study centers. Until now, less consideration has been given towards exploiting the locational intelligence of students and study centers. The lack of a locational intelligence system creates many issues for distance learners when they are assigned study centers far away from their homes. This also reduces students' socialization and interaction.

Distance education is an emerging research and development area with the integration of multidisciplinary approaches and a proliferation of disruptive technologies, such as advancements in Information Communication Technologies (ICT) which can be referred to as the usage of technology to create, manage and disseminate information, mobile technologies, the Internet of Things (IoT), and location-aware devices in the context of geospatial sciences. In this regard, AIOU has a dire need to make use of these technologies, especially geospatial technologies, in order to make informed decisions for the management of distance education for students, tutors, and exam-center allocation. Efficient use of geospatial technologies is still lacking in distance education, which makes the proposed project very interesting from both a commercial and a research standpoint.

A geographic information system (GIS) is a computer-based system that is used to manage, store, and analyze spatial data [3]. There are GIS applications in almost every field, and it can be applied when there is a need to process data in a spatial context. The system is usually computer-based interactive software that is used to make sense of data and provide support in decision-making. The current research builds on previous work [4], which highlights the importance of GIS-based support for students and study center allocation in distance learning. The study is aimed at developing a GIS-based system that takes into account the geographical locations of students, tutors, and study centers and then allocates the nearest resources to students. This increases socializing and involvement in activities organized by AIOU, as well as effective communication while learning.

The remainder of the paper is as follows: Section 2 elaborates a detailed literature review on distance education and the use of various technologies. Materials and methods for our proposed approach are outlined in Section 3. Section 4 presents interesting results and findings on the subject. Conclusions and a direction for future work are given in Section 5.

\section{Related Work}

Many studies have been conducted on the problems and issues faced by students involved in distance learning from the institutional standpoint. At the same time, numerous technological solutions to those problems have been suggested in these studies. Mir (2017) highlighted the importance of systemic support for students in open and distance learning and suggested an online integrated student support system that can reduce the administrative problems of open and distance learning (ODL) students [5]. Beldarrain (2006) pointed out that researchers are always concerned about the problems faced by distance educators and students, which need to be addressed by emerging tools and technologies [6]. The relationship between technology and learning in distance education has been proven [2]. The authors provide in-depth analysis of online learning methodologies, including concepts, strategies, and applications.

Emerging technologies such as Web 2.0 [7] are creating new opportunities for distance educators and learners in real time, which is improving the efficiency and overall effectiveness of distance education. Some of the salient features of Web 2.0 are open communication, improved social interactions, and user-generated content. These technologies when implemented bring a new dimension to distance learning by creating new models, while assigning new roles to students and instructors. Chickering and Ehrmann (1996) analyzed the use of advanced technologies in education and provided some principles for distance learning [8]; for example, fast communication between learners and instructors, prompt feedback, and quick delivery without focusing on the delivery method, which is otherwise a challenge in the absence of innovative tools and techniques.

Virtual and online university systems have accomplished various achievements in recent years. However, there are challenges in some countries because of poor communication systems, weak Internet infrastructure, and sometimes a lack of support from governments [9]. A related phenomenon 
that needs to be considered is social presence, which is of utmost importance in distance learning. Social presence can be defined as the degree to which the participants feel personally connected with their peers and instructors in the distance learning environment [10]. Social presence helps distance leaners to be comfortable interacting with peers and instructors. Social presence is a prerequisite in online learning, as it enables learners to interact and collaborate [11]. Social presence can be incorporated and increased by relying on new tools and technologies, such as computer-mediated communication (CMC) to improve the learner's comfort level.

Viberg and Grönlund (2017) discussed the use of tools and technologies by students to support learning for their flexibility, reliability, round-the-clock connectivity, and interactive nature [12]. Students learn information as convenient to them, because the information they wish to access is available to them around the clock without any issues or obstacles. Quick delivery is another major concern in open and distance learning in Pakistan, where the Government of Pakistan (GoP) and the Higher Education Commission (HEC) continuously endeavor to make the overall performance of the sector more efficient [13]. The initiatives taken by the GoP and the HEC are a step in the right direction, especially with the new national digital policy that was recently announced. However, there is still room for improvement in this sector. AIOU provides some web-based services, which are still not widely accepted due to a lack of awareness of how to access web-based systems, especially in remote areas. On the other hand, interactive systems and easy-to-use websites improve the overall effectiveness of web-based services [14].

One of the major concerns in distance education from the cognitive perspective is the transactional distance. This is defined as the cognitive space between the educator and the distance learner and the content of distance learning. Moore (1980) suggested that quality in distance learning is improved when the educator and the learner have cognitive proximity, which can be achieved by employing different strategies [15]. Reducing transactional distance can improve the learner's performance. The use of advanced database technologies that support asynchronous communication, database views (different content for instructor and learner), a question-answer database, and a student achievement database can be helpful in reducing transactional distance and increasing learner performance and have been rated well in distance learning [16].

Kagwa and Kambyashi (1997) indicated the importance of integrating advanced database technologies in distance learning, which will improve overall quality by maximizing interactions between learners and educators [17]. The use of a technology-based support system increases the interest of both learners and educators [18].

The literature discussed above analyzed and addressed different issues and problems faced by students and educators in distance learning mode during the delivery of distance education. However, a gap exists in the literature that is not addressed. From the learner's perspective, inefficient allocation is the biggest problem, which can be reduced if advanced technology is used for allocation in open and distance learning. Furthermore, the use of geospatial technologies is common in many areas such as agriculture [19], hydrology [20], land use planning [21], and natural resource management [22]. However, no considerable studies have reported on the implementation of geospatial technologies in open and distance learning to reduce learners' and educators' problems and issues. This research aims to present a real case study of AIOU and presents geospatial technologies to solve a very real problem.

Geospatial technologies such as traditional GIS sometimes do not sufficiently support the decision-making process due to a lack of analytical modeling capability [23]. This is due to the complex nature of spatial problems, which these technologies are unable to capture, and the lack of flexibility present in this kind of software. One solution to address the complexity of spatial problems is the development of spatial decision support system (SDSSs). SDSS is an interactive computer-based system designed to support single or multiple users in decision-making while solving spatial decision problems [24]. The complex nature of problems, including multiple variables, qualify the usage of SDSS in ODL. Thus, the potential of SDSS can be exploited to support decision-making in allocation problems in open and distance learning, which can be done in future studies. 


\section{Materials and Methods}

This section presents the materials and methods. First of all, data was acquired from Allama Iqbal Open University. This data predominantly consisted of addresses of students and study centers in Islamabad and Rawalpindi. The data was preprocessed for further analysis. Spatial data consisting of addresses of students and study centers was then geocoded in Google Maps by searching addresses one by one. Geocoding is the conversion of text addresses to coordinates for proper visualization in processing by GIS. This was the biggest challenge, due to the nonstandard address system in Pakistan. In Pakistan, every city has its own address scheme. One of the options we considered is that students provide their geolocations while registering online when they apply for admission to the university. This would reduce the burden of geocoding addresses manually and save a lot of time. The detailed methodology for the study is shown in Figure 1.

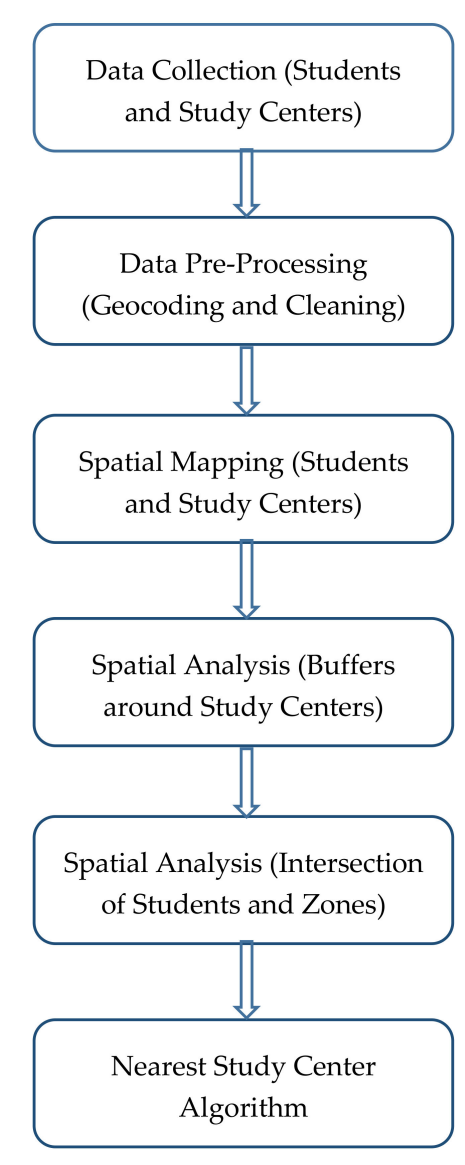

Figure 1. Detailed flowchart of methodology.

The geocoded addresses of students and study centers were visualized in ArcGIS (proprietary software developed and maintained by the Environmental Systems Research Institute, http://www.esri.com). It was assumed that study centers should be within $2 \mathrm{~km}$ of students. This would ensure that students do not face any difficulties communicating with tutors during the process of distance learning. Several scenarios were run with different distance buffers, and $2 \mathrm{~km}$ was found to be a reasonable accessible distance. Rounded buffers of $2 \mathrm{~km}$ were created around every study center, and an intersection operation was applied to the data, which provides the number of students and their details within the proximity of each buffer, indicating the suitable study center for each student. Finally, the spatial algorithm for finding the nearest study center was performed, which provides a fair picture to decision-makers on the allocation of exam centers. Section 4 presents the results and discussion. 


\section{Results and Discussion}

Geocoded locations of data (students and study centers) from Rawalpindi and Islamabad were mapped. In geocoding, textual addresses are converted to geographical coordinates. In this study, the geocoding was done by searching the text addresses and mapping them after pointing out the locations in an online mapping application. The study centers of Rawalpindi and Islamabad can be seen in Figure 2. The data is overlaid on OpenStreetMap (OSM) data, which gives fair coverage of volunteered geographic information (VGI) in the twin cities. Each study center has detailed attribute information attached, which can be seen with a single map click.

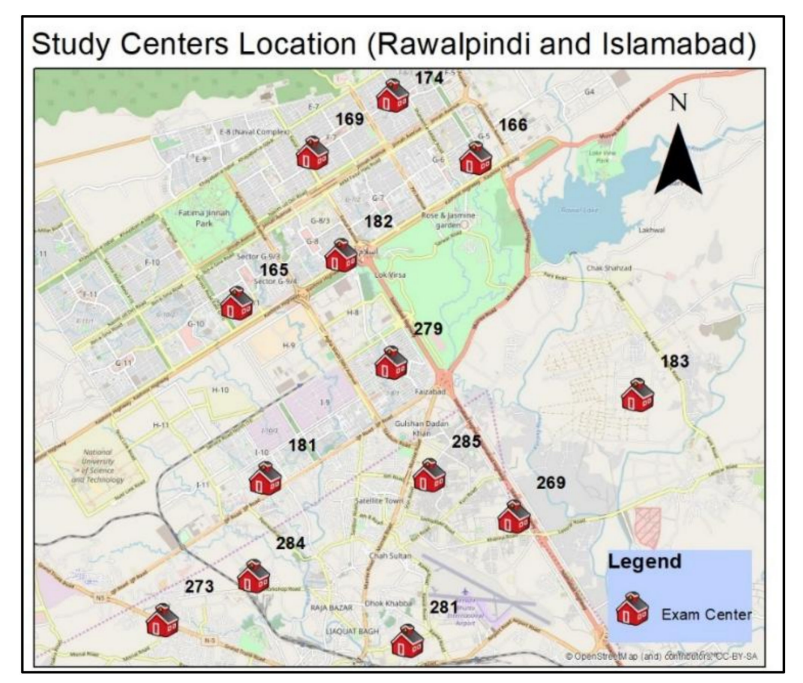

Figure 2. Study centers (Rawalpindi/Islamabad).

The next step was to map all students. Figure 3 shows the geographical spread of students across the twin cities. The map concentration can clearly be seen and can be used to get further insights, such as hot spot analysis. Each student icon on the map can be clicked or searched to bring up detailed information for the university administration (see Figure 4).

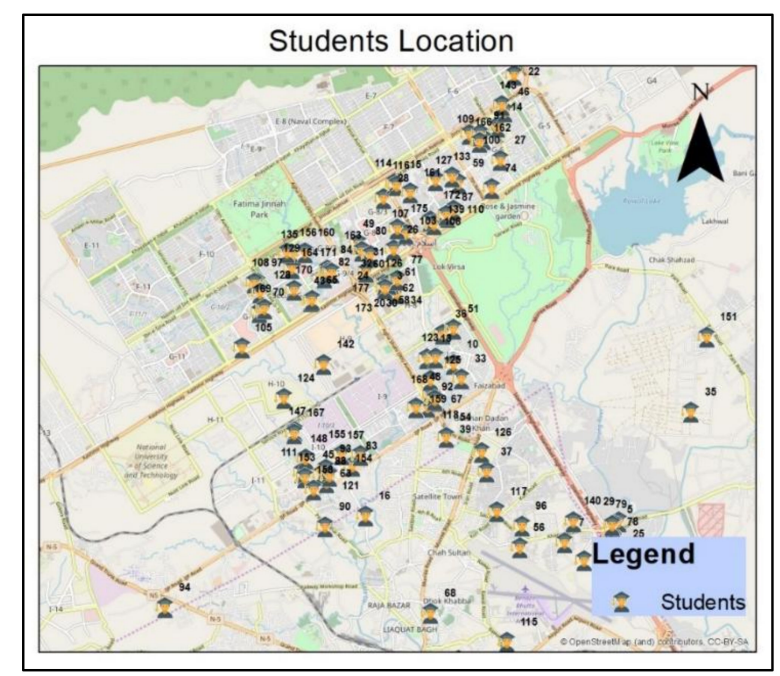

Figure 3. Student locations (Rawalpindi/Islamabad). 


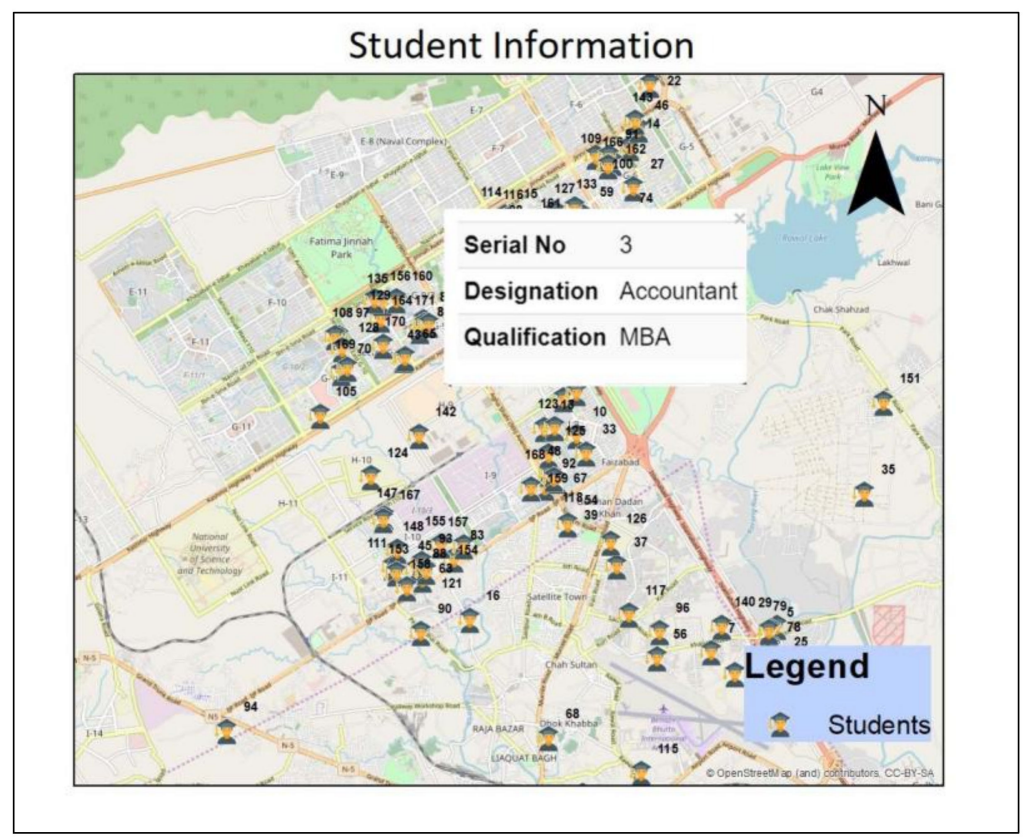

Figure 4. Student information.

Two kilometers is assumed as a feasible distance to ensure easy interaction between students and their tutors and study centers. The algorithm autogenerated a $2 \mathrm{~km}$ buffer around each study center. This indicates that the students residing in those areas are suitable for assignment to that specific study center. This is demonstrated in Figure 5.

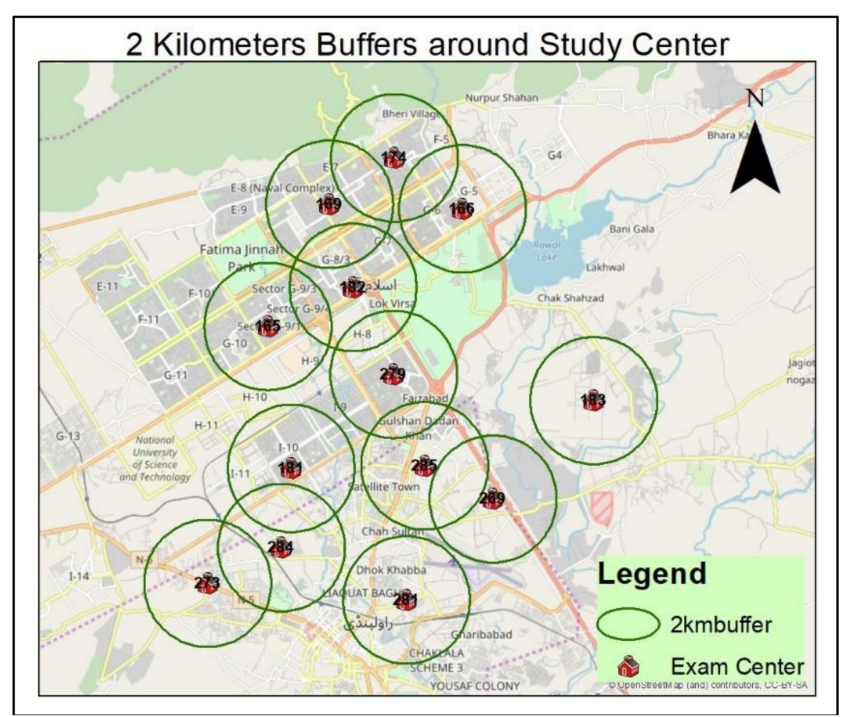

Figure 5. Two kilometer buffer around study centers.

The next step was to assign the study center to each student. The algorithm was run on the available dataset. The results can be seen in Figure 6, where each student is assigned a tutor based on proximity. For a detailed analysis, a spatial query was formulated to see which exam centers were assigned to which students. The web interface is interactive and supports similar spatial queries, which will assist management with planning on the map. 


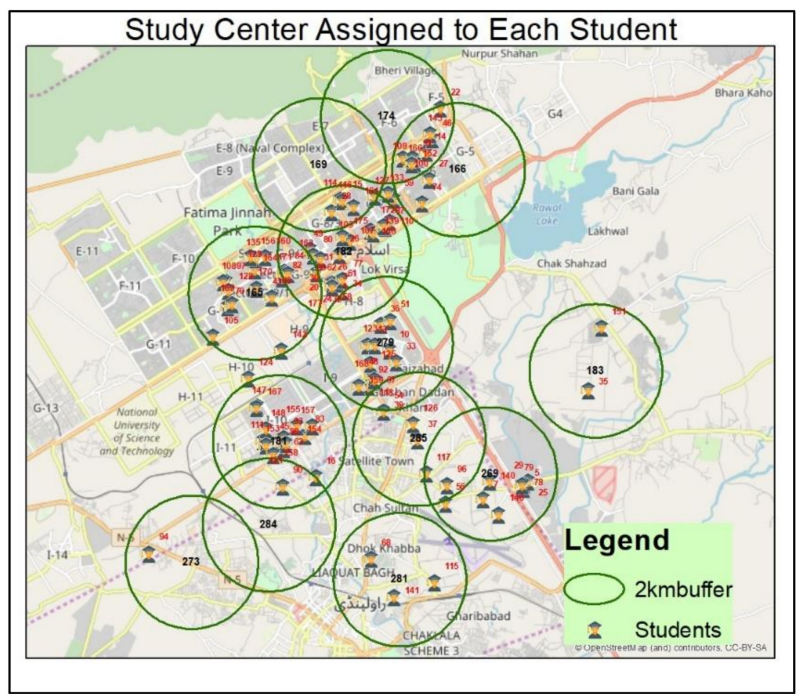

Figure 6. Study center allocation.

Table 1 shows that center 281 is allocated to students with identification numbers 141, 115, and 68 . This indicates that only three students are assigned to that center. There is also a complicated case where one student is assigned to more than one exam center, i.e., student number 96 was assigned to study centers 269 and 285 .

Table 1. Study centers allocated to students.

\begin{tabular}{|c|c|c|}
\hline Center ID & Center Name & Student ID \\
\hline 281 & Sirsyed High School, Tipu Road, Rawalpindi & 141 \\
\hline 281 & Sirsyed High School, Tipu Road, Rawalpindi & 115 \\
\hline 281 & Sirsyed High School, Tipu Road, Rawalpindi & 68 \\
\hline 273 & Govt. Degree College for Women, Peshawar Road, Near Chour Chowk, Rawalpindi & 94 \\
\hline 269 & Govt. Faiz ul Islam High School No. 2, Shakrial, Near Zia Masjid, Rawalpindi & 146 \\
\hline 269 & Govt. Faiz ul Islam High School No. 2, Shakrial, Near Zia Masjid, Rawalpindi & 56 \\
\hline 181 & Islamabad Model College for Boys, St. No. 17, I-10-1, Islamabad & 90 \\
\hline 284 & Govt. Higher Secondary School, Loco Shed, Near Railway Hospital, Rawalpindi & 90 \\
\hline 269 & Govt. Faiz ul Islam High School No. 2, Shakrial, Near Zia Masjid, Rawalpindi & 96 \\
\hline 285 & Govt. Comprehensive Boys High School, Dhoke Kashmirian, Rawalpindi & 96 \\
\hline 269 & Govt. Faiz ul Islam High School No. 2, Shakrial, Near Zia Masjid, Rawalpindi & 79 \\
\hline 269 & Govt. Faiz ul Islam High School No. 2, Shakrial, Near Zia Masjid, Rawalpindi & 25 \\
\hline 281 & Sirsyed High School, Tipu Road, Rawalpindi & 141 \\
\hline 281 & Sirsyed High School, Tipu Road, Rawalpindi & 115 \\
\hline 281 & Sirsyed High School, Tipu Road, Rawalpindi & 68 \\
\hline 273 & Govt. Degree College for Women, Peshawar Road, Near Chour Chowk, Rawalpindi & 94 \\
\hline 269 & Govt. Faiz ul Islam High School No. 2, Shakrial, Near Zia Masjid, Rawalpindi & 146 \\
\hline 269 & Govt. Faiz ul Islam High School No. 2, Shakrial, Near Zia Masjid, Rawalpindi & 56 \\
\hline
\end{tabular}

Study center 269 is located in Shakrial, Near Zia Masjid, Rawalpindi, which is close to study center 285, located near Chour Chowk, Rawalpindi. The distance between the study centers is $2.85 \mathrm{~km}$, while their distances from the residential address of student 96 are $1.63 \mathrm{~km}$ and $1.8 \mathrm{~km}$, respectively. This brings the student within $2 \mathrm{~km}$ of both study centers. There is a filtering mechanism in tier 2 of the algorithm that resolves this complexity.

The mean distance between students and proposed study centers was found to be $1227 \mathrm{~m}$. This is deemed feasible for travelling to and communicating with the study center. For further descriptive statistics, the mode and median of distance between students and proposed study centers were calculated and found to be 1101 and $1246 \mathrm{~m}$, respectively. This is not too far from the mean and shows that the distance between students and proposed study centers is relatively normally distributed around the mean. The minimum and maximum distances reported by the algorithm were 191 and 
$1927 \mathrm{~m}$, respectively. These distances may vary when the study is expanded for other cities or rural areas, as the geographical spread of students and study centers will be much extended. Figure 7 shows the distances between students and proposed study centers along with the average distance.

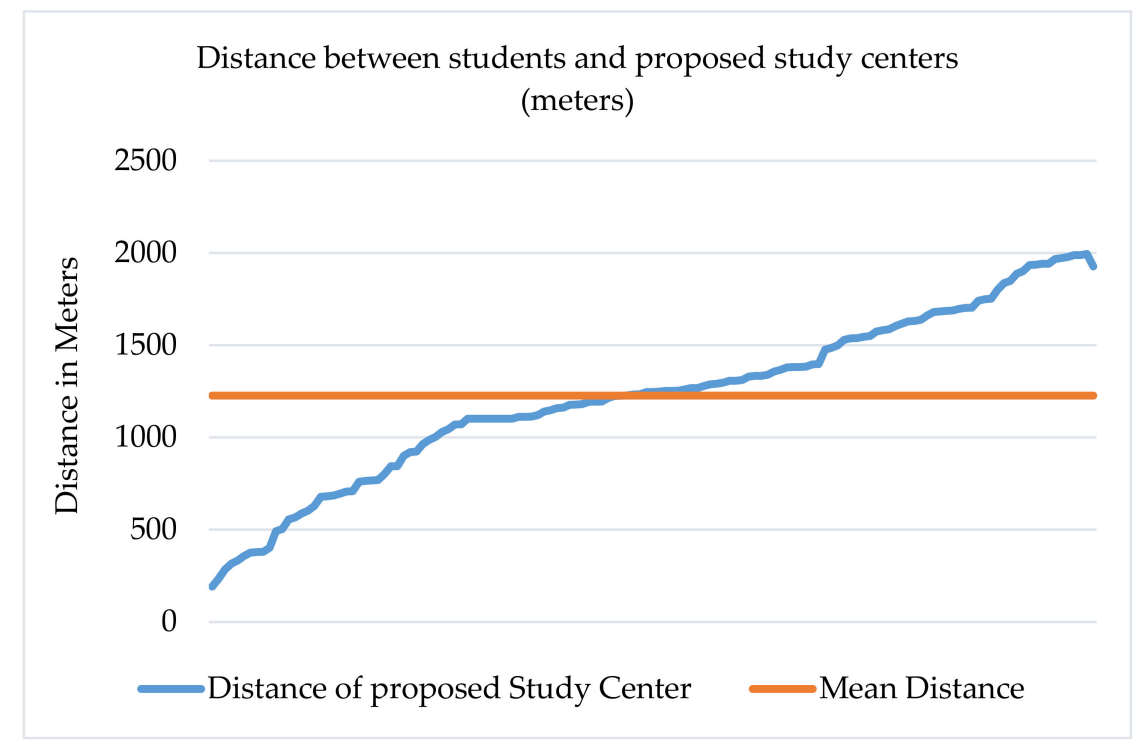

Figure 7. Distances between students and study centers, and mean distance (meters).

The percentage of students assigned to each study center is illustrated in Figure 8. The most students (27.34\%) were assigned to center 182, Islamabad Model School for Boys, in Sector G/8-4, Islamabad. The reason for such a high number of assignments is high clustering of students in proximity to the center. The fewest students $(0.72 \%)$ were assigned to study center 273 , the Govt. Degree College for Women, Peshawar Road, near Chour Chowk, Rawalpindi. This is also due to the fact that fewer students live in close proximity to study center 273 . This may create problems in areas where the spread of distance learning students and study centers is not uniform and the feasible distance of $2 \mathrm{~km}$ has to be changed to prevent over- and under allocation by the proposed algorithm.

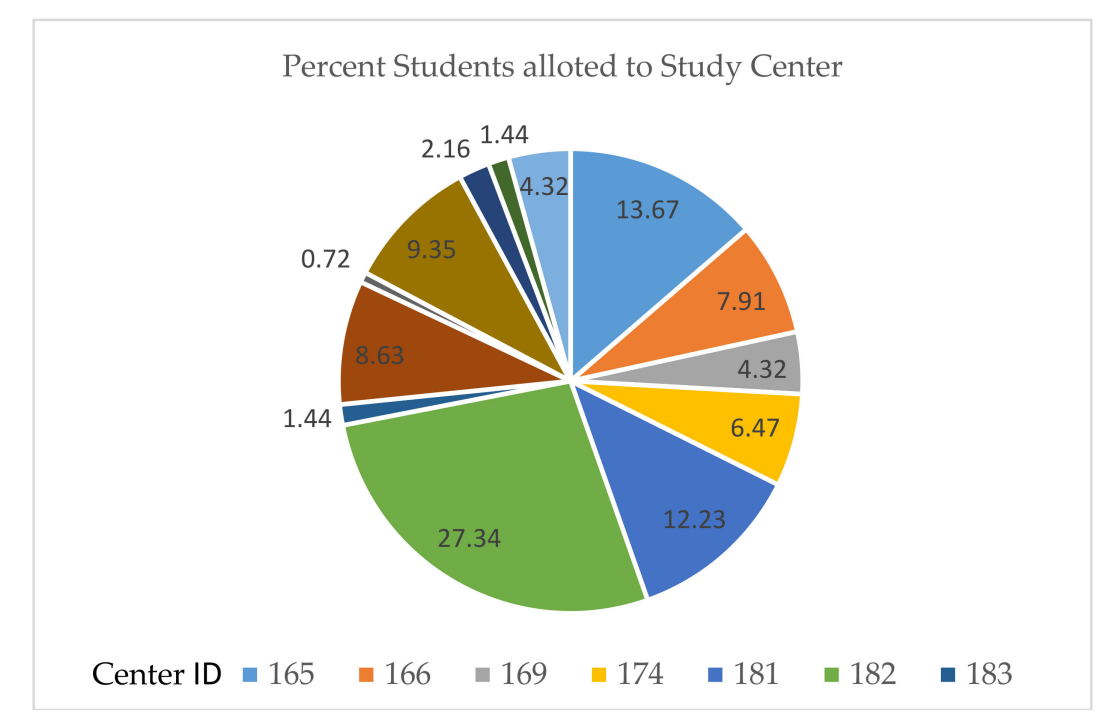

Figure 8. Percentage of students assigned to each study center. 


\section{Conclusions}

This study proves that geospatial technologies can be efficiently used to address allocation problems in open and distance learning. Deploying simple yet effective techniques can help to improve the overall operational capacity of distance education, including allocation. Assigning distance educators and study centers based on geographical proximity will help reduce the physical and cognitive distance between learners and distance educators, which is needed to improve the performance of ODL education, especially in the case of AIOU.

There are a few limitations associated with this study that need to be addressed and improved. For example, the proposed system must be interoperable with the existing system of AIOU. Currently they have slightly different architectures, and our proposed technological stack can easily be integrated. Geocoding in longer runs needs to be automated. At present, there is no standard scheme for residential addresses that is uniformly followed across the country. However, standardized addresses can be proposed where existing addresses can fit, with the help of an efficient algorithm. Another aspect is related to assigning distance proximity. This can result in overallocation in urban areas where the population density is higher and under allocation in rural areas where the population density is lower. This is left for future work.

Study center allocation in this study only takes into account the student's geographical location and does not take into account other necessary details for allocation, such as course details, student gender, the discipline the student is enrolled in, and facilities available in the study center. Similarly, this work can be further expanded by including analytics in future studies. Online and distance leaners create huge amounts of semi-structured data, which can be used to make informed decisions. Analytics plays a vital role in designing new applications utilizing the data provided by users interacting with different applications [25].

SDSS has the potential to address the issue of allocation in a more detailed manner as compared to simple geospatial technologies. AIOU is the largest open and distance learning institution in Pakistan, and can exploit the potential of SDSS for allocation of tutors and study centers considering multiple factors and different alternatives. Online and distance learning education has a large base of potential users all over the world, as fewer resources are needed to acquire skills. Online and distance learning inflow has been roughly $\$ 6$ billion over the last five years [26]. This implies that systems designed to solve allocation problems in online and distance learning have the potential to target the industry and make an impact.

The lack of analytical modelling capabilities in traditional geospatial technologies makes the decision-making process less effective. The complex nature of spatial problems makes it difficult for these technologies to capture the complexity of the problem. This can be addressed by introducing SDSS coupled with modelling techniques, such as agent-based modeling and simulation (ABMS). ABMS simulates the behavior of individual entities known as agents and assesses the effects of those agents on the whole system. The ability of spatial ABMS to simulate the actions of individual agents will open up new avenues in research on allocation in open and distance learning, where many other behaviors and interactions can be modelled along with geographic location to make allocation more effective.

Although the study proved to be effective in solving the allocation problem in the twin cities, in the future we aim to make a completely independent and integrated web-based software solution that will harness the potential of SDSS and ABMS to address allocation problems.

Author Contributions: S.N.K. carried out data analysis. A.T. and K.M. designed the methodology of this study. A.A. and Z.N. assisted in formulating the results and discussions. S.A.G. helped in data acquisition and refinement of the methodology.

Acknowledgments: This study is financially supported by the Higher Education Commission (HEC) of Pakistan under the National Research Program for Universities (NRPU). Data for this study was provided by Allama Iqbal Open University (AIOU), Islamabad. The authors gratefully acknowledge their support.

Conflicts of Interest: The authors declare no conflict of interest. 


\section{References}

1. Keegan, D. Concepts: Problems in defining the field of distance education. Am. J. Distance Educ. 1988, 2, 4-11. [CrossRef]

2. Dabbagh, N.; Bannan-Ritland, B. Online Learning: Concepts, Strategies, and Application; Prentice Hall: Upper Saddle River, NJ, USA, 2005.

3. Chang, K.T. Geographic Information System; John Wiley \& Sons, Ltd.: New York, NJ, USA, 2006.

4. Mir, K. Design and Development of Online Student Support System. Pak. J. Distance Online Learn. 2017, 3, 1-8.

5. Mir, K.; Kanwal, S. Spatial Decision Support System for Tutor and Study Centre Allocation for Distant Learning Institutes/System; AIOU: Islamabad, Pakistan, 2013.

6. Beldarrain, Y. Distance education trends: Integrating new technologies to foster student interaction and collaboration. Distance Educ. 2006, 27, 139-153. [CrossRef]

7. O'Reilly, T. What Is Web 2.0? Design Patterns and Business Models for the Next Generation of Software. 2005. Available online: http:/ / oreillynet.com/1pt/a/6228 (accessed on 9 November 2017).

8. Chickering, A.W.; Ehrmann, S.C. Implementing the seven principles: Technology as lever. AAHE Bull. 1996, 49, 3-6.

9. Darkwa, O.; Mazibuko, F. Creating virtual learning communities in Africa: Challenges and prospects. First Monday 2000, 5. [CrossRef]

10. Lowenthal, P.R.; Dennen, V.P. Social Presence, Identity, and Online Learning: Research Development and Needs. Distance Educ. 2017, 38, 137-140. [CrossRef]

11. Ubon, N.A.; Kimble, C. Exploring social presence in asynchronous text-based online learning communities (OLCS). In Proceedings of the 5th International Conference on Information Communication Technologies in Education, Samos, Greece, 1-3 July 2004; pp. 292-297.

12. Viberg, O.; Grönlund, Å. Understanding students' learning practices: Challenges for design and integration of mobile technology into distance education. Learn. Media Technol. 2017, 42, 357-377. [CrossRef]

13. Arif, M.; Ameen, K.; Rafiq, M. Assessing distance education students satisfaction with web-based services: A Pakistani's perspective. Online Inf. Rev. 2017, 41, 202-218. [CrossRef]

14. Wijayaratne, A.; Singh, D. Is there space in cyberspace for distance learners with special needs in Asia? A review of the level of Web accessibility of institutional and library homepages of AAOU members. Int. Inf. Libr. Rev. 2010, 42, 40-49. [CrossRef]

15. Moore, M.G. Theory of transactional distance. Theor. Princ. Distance Educ. 1993, 1, 22-38.

16. Rabinovich, T.; Berthon, P.; Fedorenko, I. Reducing the distance: Financial services education in web-extended learning environments. J. Financ. Serv. Mark. 2017, 22, 126-131. [CrossRef]

17. Kagawa, O.; Kambayashi, Y. Advanced database functions for distance education system: VIEW classroom. In Proceedings of the IEEE International Database Engineering and Applications Symposium (IDEAS'97), Montreal, QC, Canada, 25-27 August 1997; pp. 231-239.

18. Yoshino, T.; Munemori, J.; Yuizono, T. Development and application of a distance learning support system using personal computers via the Internet. In Proceedings of the IEEE 1999 International Conference on Parallel Processing, Wakamatsu, Japan, 21-24 September 1999; pp. 395-402.

19. Bill, R.; Nash, E.; Grenzdörffer, G. GIS in Agriculture. In Springer Handbook of Geographic Information; Springer: Berlin/Heidelberg, Germany, 2011; pp. 461-476.

20. Clark, M.J. Putting water in its place: A perspective on GIS in hydrology and water management. Hydrol. Process. 1998, 12, 823-834. [CrossRef]

21. Ventura, S.J.; Niemann, B.J.; Sutphin, T.L.; Chenoweth, R.E. GIS-enhanced land-use planning. In Community Participation and Geographic Information Systems; Taylor and Francis: Oxfordshire, UK, 2002; pp. 113-124.

22. McCall, M.K.; Minang, P.A. Assessing participatory GIS for community-based natural resource management: Claiming community forests in Cameroon. Geogr. J. 2005, 171, 340-356. [CrossRef]

23. Densham, P.J. Spatial decision support systems. Geogr. Inf. Syst. Princ. Appl. 1991, 1, 403-412.

24. Malczewski, J. GIS and Multi-Criteria Decision Analysis; John Wiley \& Sons: New York, NJ, USA, 1999. 
25. Sangi, N.A.; Mir, K.; Tahir, M.A. Using Analytics to Improve Learner-Centered Application Design; Commonwealth of Learning: Vancouver, BC, Canada, 2016.

26. Piccioli, V. E-Learning Market Trends E Forecast 2014-2016 Report; Docebo: Athens, GA, USA, 2014.

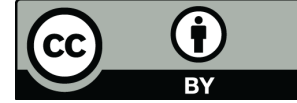

(C) 2018 by the authors. Licensee MDPI, Basel, Switzerland. This article is an open access article distributed under the terms and conditions of the Creative Commons Attribution (CC BY) license (http://creativecommons.org/licenses/by/4.0/). 